\section{Abstractions}

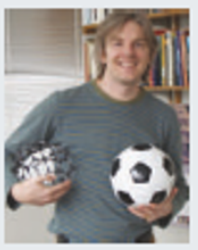

\section{SENIOR AUTHOR}

Complexinorganic nanoparticles are of great interest to materials scientists. Butlearning about their structure is difficult, because Xray crystallography often fails on these tiny molecules. Researchers at Michigan State University in East Lansing decided to see if they could combine one-dimensional data with mathematical modelling and computation to predict the three-dimensional structure.

They reasoned that if they measured the distance between pairs of atoms, they could use computers towork out the matching threedimensional structure. Onpage 655, Simon Billinge andhis colleagues present an algorithm based on UK soccer leagues that seems to be able to work out the structures.

How does the soccer analogy ap ply to atomic structure?

In soccer, you have promotion and relegation. Teams that winget promoted to a higher level and those that lose get relegated to a lower level. Relegated teams earn lessmoney and sell their worst player, whereas promoted teams can buy new players. The atoms are the players, and clusters of atoms are the teams.

Where did you get this ins piration from? The basic ideas grew out of conversations about soccer withmy postdoc, Pavol Juhás. Iguess we spent too much time watching European soccergrowing up.

What's this method's biggest advantage? Relegation gives you a way to backtrack it turns out that this algorithm is really efficient. Maybe soccer teams could use it.

What's new about this?

We demonstrated for the first time that it is possible to get unique three-dimensional nanoparticle structures from onedimensional diffraction data.

What's the next step?

This was a proof of principle. All that we've solved is the buckyball - a structure that's already known. We need to use this approach to solve a more complex, unknown nanoparticle structure.

What footb all team do you sup port? I have supported Arsenal since I was aboy and right now they are playing themost beautiful football.

What molecule do you support? It would have to be buckyball. Because in this case, buckyball won theleague.

What other British pastime could you use to create algorithms?

Maybe our next algorithm could be inspired by discussions of the weather.

\section{MAKING THE PAPER}

Giulio Superti-Furga

\section{A joint effort - and 52,000 samples - shed light on protein complexes.}

For four days last July, Giulio Superti-Furga, Robert Russell and a few of their colleagues shut themselves away in a hotel room on the banks of the Danube. There they pored over thousands of images of yeast proteins. They were scouring the pictures to try to work out whether most cellular proteins exist as complexes and to see how they are organized.

The fruits of their labour appear on page 631 of this issue, where they confirm that the proteins do indeed form hundreds of 'core' complexes. But they also show that these core complexes can combine with other proteins to gain additional capabilities - much like extra tool modules can be attached to a machine.

The quest for the complexes began some six years ago at Cellzome, the biotechnology firm co-founded by Superti-Furga in Heidelberg, Germany. The initial plan was to characterize all of the detectable protein complexes in a cell - the team picked yeast as it is a relatively simple and well-studied model system.

Anne-Claude Gavin, the paper's joint first author, led the effort to express all of the known yeast proteins with a small tag that would allow each one to beextracted from the cell along with any other protein bound to it. The researchers then used mass spectrometry to identify the captured proteins and their partners.

A trial run for this technique, using a subset of yeast's proteins, was published a few years ago (A.-C. Gavin et al. Nature 415, 141-147; 2002). It revealed that protein complexes are indeed the rule rather than the exception. But in the latest results, the team also fished for different binding partners for each protein several times, eventually collecting data from 52,000 samples. "By doing the entire protein complement, there is nowhere a protein can hide," says Superti-Furga. "We would have not seen the modularity otherwise."

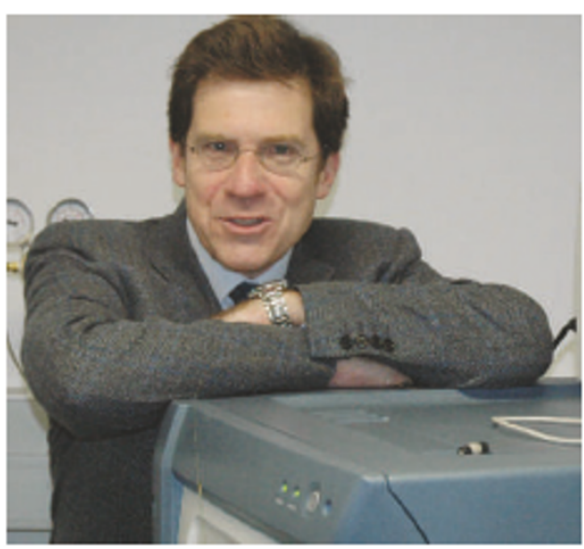

Gathering such a massive amount of data may seem like a daunting task, but the real challenge still lay ahead: converting the information into something biologically meaningful. Superti-Furga turned for help to Russell, a bioinformatician at the European Molecular Biology Laboratory in Heidelberg. "Getting first access to original data that are very exciting is a dream come true for a bioinformatician," says Russell, who worked with Patrick Aloy on the analysis.

The process of getting from data to meaning involved much trial and error - and a lot of back-and-forth communication between the labs to reach a consensus. "An important element was the very intense discussions between biologists and bioinformaticians. That was the best part of the project, and where the magic happened," says Superti-Furga, who recently left Cellzome to head the Research Center for Molecular Medicine at the Austrian Academy of Sciences in Vienna.

Apart from meetings in European hotels, these discussions took place on the phone and by e-mail over several months. Russell alone counts some 1,020 messages in his inbox relating to the project.

By explaining the data from each member's perspective, the group eventually arrived at a common interpretation. "You have to keep trying to describe what you think you are seeing and the other person keeps trying to see whether they understand," says Superti-Furga.

\title{
QUANTIFIED IRELAND
}

\section{A numerical pers pective on Nature authors.}

Gerard Cagney is a member of the large team that this week describes the proteinmachines needed for a simple yeast cell towork (see page 637). During the experimental work, Cagney was living and working in Canada. But he recently moved to the Conway Institute of Biomolecular and Biomedical Research in Dublin, Ireland, as the principal investigator of a proteomics lab.

The govemment is doing allitcan tomake Ireland researchfriendly, says Cagney - through agencies such as Science Foundation Ireland, which works closely with the Industrial DevelopmentAgency to attract industrial investment. But ultimately, Cagney says, what makes the labsuccessful is the talented and hard-working group of researchers who all, like himself, enjoy their work and love science.
4 manuscripts submitted to Nature in 2006 have come from Ireland $(<1 \%$ of total submissions).

16 papers published in Nature this year have focused on protein wark ( $7 \%$ of total papers published).

53 authors, including Cagney, collaborated on the yeast paper published on page 637 this week.

4,562 is the number of tagged proteins that Cagney and his colleagues processed. 